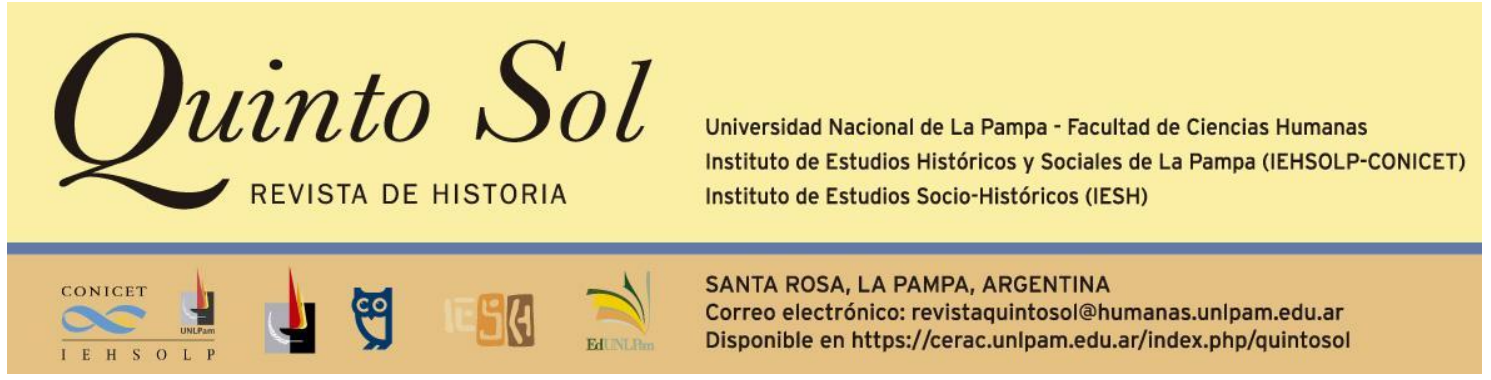

Quinto Sol, vol. 25, n 3, septiembre-diciembre 2021, ISSN 1851-2879, pp. 1-19

https://doi.org/10.19137/qs.v25i3.5464

Esta obra se publica bajo licencia Creative Commons 4.0 Internacional. (Atribución-No Comercial-

Compartir Igual)

\title{
Elites entre el mundo social y el cultural. El Club Social y el Ateneo de Córdoba (1870-1913)
}

\author{
Elites between social and cultural worlds. The Club Social and \\ the Ateneo de Córdoba (1870-1913)
}

\section{Elites entre o mundo social e o cultural. 0 Clube Social e o Ateneu de Córdoba (1870-1913)}

\author{
María Victoria López \\ Consejo Nacional de Investigaciones Científicas y Técnicas \\ Universidad Nacional de Córdoba. Instituto de Antropología de Córdoba \\ Argentina \\ Correo electrónico: victorialopez84@gmail.com
}

\begin{abstract}
Resumen
Este artículo explora el proceso de emergencia de una fracción culturalintelectual de las elites en Córdoba, Argentina, desde el punto de vista del asociacionismo cultural y recreativo. Se entiende al asociacionismo como expresión formalizada de la sociabilidad estamental capaz de expresar, a la vez, las tensiones y transformaciones que experimentaron esas elites entre 1870 y 1913. Analizamos dos asociaciones locales, el Club Social, fundado en 1871 y existente en la actualidad, y el Ateneo de Córdoba (1894 a 1913), considerando sus semejanzas y diferencias en cuanto al perfil de los socios, objetivos, actividades y representaciones ligadas a cada una. Sostenemos que, además de funcionar como mecanismos de construcción de la distancia social, estas asociaciones expresaron la fragmentación interna de la elite, en tanto contribuyeron a delimitar una fracción específicamente cultural o intelectual dentro de la elite social más general, definida por criterios socioeconómicos más amplios. Mientras el Club incorporaba a miembros de todas las fracciones, el Ateneo establecía un recorte en el
\end{abstract}

\author{
Palabras \\ clave \\ elites \\ asociaciones \\ diferenciación \\ social \\ distinción
}


universo de posibles socios que puede iluminar aspectos desatendidos de la diversificación de las elites en el giro de siglo. Trabajamos con documentación asociativa como reglamentos, estatutos y memorias institucionales, además de prensa diaria y revistas.

\section{Abstract}

This article explores the process of emergence of a cultural-intellectual fraction of the elites from Córdoba, Argentina, viewed from cultural and recreational associationism. Associationism is understood as a formalized expression of the estamental sociability capable of expressing, at the same time, the tensions and transformations experienced by those elites between 1870 and 1913. We analyze two local associations, the Social Club, founded in 1871 and still existing today, and the Ateneo de Córdoba (1894-1913), showing their similarities and differences in terms of profile of the members, objectives, activities and representations linked to each association. We argue that, in addition to functioning as mechanisms for constructing social distance, such associations revealed the internal fragmentation of the elite, insofar as they contributed to delimiting a specifically cultural or intellectual fraction within the more general social elite, defined by broader socio-economic criteria. While the Club incorporated members from all fractions, the Ateneo cut down on the universe of possible members. Hence, this can illuminate neglected aspects of the diversification of the elites at the turn of the century. We worked with associative documentation such as bylaws, statutes and institutional memories, in addition to daily press and magazines.

\section{Resumo}

Este artigo explora o processo de emergência de uma fracção culturalintelectual das elites em Córdoba, Argentina, desde o ponto de vista do associacionismo cultural e recreativo. Entende-se o associacionismo como a expressão formalizada da sociabilidade estamental capaz de expressar, por sua vez, as tensões e transformações que experimentaram essas elites entre 1870 e 1913 . Analisamos duas associações locais, o Clube Social, fundado em 1871 e existente na atualidade, e o Ateneu de Córdoba (1894 a 1913), considerando suas semelhanças e diferenças quanto ao perfil dos sócios, objetivos, atividades e representações unidas a cada uma. Sustentamos que, além de funcionar como mecanismos de construção de distanciamento social, estas associações expressaram a fragmentação interna da elite em tanto contribuíram a delimitar uma fracção especificamente cultural ou intelectual dentro da elite social mais geral, definida por critérios socioeconômicos mais amplos. Enquanto o clube incorporava a membros de todas as fracções, o Ateneu estabelecia um recorte no universo de possíveis sócios que podem iluminar aspectos não atendidos da diversificação das elites na virada do século. Trabalhamos com documentação associativa como regulamentos, estatutos e memórias institucionais, ademais da imprensa diária e revistas.

\section{Keywords}

elites

associations

social

diversification

distinction

\section{Palavras-chave}

elites

associações

diferenciação social

distinção 


\section{Elites entre el mundo social y el cultural. El Club Social y el Ateneo de Córdoba (1870-1913)}

\section{Introducción}

Las elites en la Argentina de fines del siglo XIX y comienzos del XX han sido muy estudiadas en sus dimensiones política y económica: las imágenes del "régimen oligárquico" y el "granero del mundo", aunque perimidas, dan cuenta de su largo protagonismo en esas áreas de la historiografía. Menos atención recibieron, relativamente, los aspectos culturales y simbólicos, aunque en los últimos años han sido el eje de nuevos estudios sobre las elites de fines del siglo XIX, como muestran los trabajos de Leandro Losada $(2008,2009)$ y Roy Hora (2014), entre otros. Respecto de la sociabilidad cultural e intelectual, abrieron nuevas perspectivas las investigaciones de Pilar González Bernaldo (2001), Carlos Altamirano (2008) y Paula Bruno (2014), por mencionar algunos. Entre otros puntos, mostraron que examinar los aspectos culturales de la vida social puede iluminar cuestiones centrales de la estructuración social y ofrecer un ángulo para observar procesos de diferenciación en contextos de profundas transformaciones.

Como ya ha sido descripto ampliamente por múltiples investigaciones, el giro de siglo fue un momento inédito de prosperidad económica -con grandes variaciones regionales-, complejización social y organización política, entre cuyos principales elementos se cuentan la integración al mercado mundial, la inmigración masiva, la urbanización, los cambios en la estructura social y en las relaciones entre las clases, y la consolidación del Estado central y del sistema de gobierno (Zimmerman, 2000).

En Córdoba, esa prosperidad estuvo asociada al crecimiento de la región sudeste de la provincia -progresivamente integrada a la economía agroexportadora pampeana-, en paralelo con la decadencia de la región noroeste, donde, desde el siglo XVIII, se habían concentrado la actividad ganadera y la comercial, así como la riqueza, el prestigio y el poder político de larga data. Ese cambio en el polo económico provincial tuvo un correlato social en la fractura de la vieja elite criolla, de origen colonial e independentista, algunos de cuyos miembros emprendieron una reconversión exitosa al nuevo modelo; los que no lo lograron quedaron con poco más que el linaje, las tradiciones y la cultura.

En paralelo a estas transformaciones, el mundo social de las elites también cambió: la vida pública se expandió al ritmo de la modernización urbana; el asociacionismo cultural y el recreativo crecieron; el estilo de vida como la sociabilidad de las elites se formalizaron al adoptar códigos de comportamientos ritualizados en salones, visitas, paseos y todo ámbito de interacción. Similares transformaciones fueron observadas en las ciudades más pobladas y cosmopolitas, como Buenos Aires y Rosario. Como en esas y otras ciudades de Argentina, la "alta sociedad" de la capital 
cordobesa estuvo constituida por miembros de las elites políticas, económicas, sociales y culturales, tramadas en una compleja interrelación (Losada, 2008). Al inicio de la etapa considerada, la elite social en la ciudad era todavía, en gran medida, una de tipo notabiliar, cuyos diferentes fundamentos de poder social pueden distinguirse analíticamente, aunque se manifestasen de manera indiferenciada. La riqueza -fuera comercial, terrateniente o inmobiliaria-, el prestigio -asociado a linaje y apellido-, el título universitario y, como corolario de los anteriores, las posibilidades de ejercer el poder político constituían fuentes de poder alternativas y no mutuamente excluyentes. Así, tenemos a un sector que gobierna, maneja las principales ramas de la economía, ostenta un prestigio social casi indisputado y se considera guía cultural y espiritual de la sociedad; se trata de una elite del poder "total" que asume que su posición económica y social debe traducirse, naturalmente, en poder político (Agüero y López, 2017). Esto ocurría más por la "indiferenciación" de los capitales en cuestión que por una acumulación de singulares especies de capital (Martínez, 2006). Esta heterogeneidad implica suponer, en el seno de este grupo social, la mezcla de profesiones, de vías de sustento material, de referencias ideológicas y culturales, de posturas políticas y de antigüedad familiar, en un entorno mayoritariamente hispanocriollo que habilitaba contadas integraciones de extranjeros.

Los fundamentos del poder social de estas elites "totales" experimentaron profundas transformaciones en el período: la mencionada reorientación pampeana de la economía, con el consiguiente ascenso de nuevos nombres; el impacto de la inmigración en ese proceso; la reparación simbólica de esa fractura por vía del reclamo de linaje; la relativa devaluación del título universitario debido a su incipiente extensión a otros sectores y la profesionalización y nacionalización de la política, junto con la ampliación de elencos políticos y la emergencia de partidos modernos; procesos que en su interrelación trastocaron sus modos de reproducción como estamento o grupo social. Una de las consecuencias fue la fragmentación al interior de las elites y la emergencia de una fracción específica, la cultural-intelectual, que se desprendió progresivamente de aquellas. Esta demandaba nuevas credenciales ligadas a la producción y el consumo simbólicos y se presentaba relativamente más abierta a individuos provenientes de otros orígenes sociales, al tiempo que se mantenían las instancias que daban cohesión a todas las fracciones.

En este artículo exploramos el proceso de emergencia de una fracción culturalintelectual de las elites en Córdoba, desde el punto de vista del asociacionismo cultural y recreativo; entendido este último como expresión formalizada de la sociabilidad estamental y como capaz, a la vez, de expresar las tensiones y transformaciones que experimentaron estos grupos entre 1870 y la primera década del siglo XX. Analizamos dos asociaciones del movimiento asociativo local, el Club Social -fundado en 1871 y existente en la actualidad- y el Ateneo de Córdoba -1894 a 1913-, a fin de considerar sus semejanzas y diferencias en cuanto al perfil de sus socios y a los objetivos, actividades y representaciones vinculados a cada una. Sostenemos que, además de funcionar como mecanismos de construcción de la distancia social, estas prácticas asociativas expresaron -en el ámbito que les era propio- la fragmentación interna de la elite, en tanto contribuyeron a delimitar una fracción específicamente cultural o intelectual dentro del estamento en general, definida por criterios socioeconómicos más amplios. La comparación de estas dos asociaciones permite observar zonas de 
superposición y de exclusión entre los mundos social y cultural de las elites. Si bien ambas instituciones tuvieron como objetivo genérico el fortalecimiento de los vínculos intraelite y la distinción social del grupo respecto de la sociedad en general, una asociación como el Ateneo se orientaba claramente hacia diversas formas de una "alta cultura" que servía para establecer diferencias al interior mismo de la elite. No todos los miembros podían formar parte del Ateneo por su sola pertenencia estamental-como sí ocurría en el caso del Club Social-, porque se les requerían intereses y prácticas intelectuales específicos.

Como señaló Marc Bloch (1993) hace muchos años, la comparación como instrumento puede ayudar a desenmascarar analogías aparentes y establecer diferencias relevantes. Las asociaciones consideradas cumplían una función distinta de otras contemporáneas que integraban a los emergentes sectores medios o a los nuevos sectores profesionales en el seno de las elites tradicionales, como ocurría con la Sociedad Sarmiento en Tucumán (Vignoli, 2015), o las sociedades bahienses estudiadas por María de las Nieves Agesta (2015). En el primer caso, se trató de una iniciativa de alumnos y egresados de la Escuela Normal y del Colegio Nacional de San Miguel de Tucumán que rápidamente incorporó a grupos profesionales emergentes que pertenecían a sectores medios urbanos. Señala Marcela Vignoli (2015) que la Sociedad Sarmiento tuvo un rol clave en la creación de un ambiente cultural y asociativo que estuvo en el origen de la Universidad local. En este caso, la Sociedad fue clave para que estos nuevos sectores lograsen notoriedad en el espacio público, "hasta entonces reservado a representantes de la elite social" (p. 16). En el segundo caso, las bahienses Asociación Bernardino Rivadavia (1882) y Asociación Cultural Bahía Blanca (1919) se orientaron a la creación y consolidación de capitales sociales que legitimaran la inclusión de nuevos sectores sociales profesionales en la elite local, de origen reciente y ligada a la creación misma de la ciudad, en 1828. En cambio, el Club Social y el Ateneo de Córdoba fueron producto de la sociabilidad estamental y, por tanto, su pequeña masa de socios se recortaba del conjunto de las elites locales. Aunque, como veremos, contaron con diferentes grados de apertura y modalidades de ingreso, no se constituyeron, al menos en esta etapa, en espacios de integración de nuevos sectores.

El movimiento asociativo ha sido considerado, en su globalidad, como un indicador de la conformación y consolidación de una esfera pública moderna, en la línea de estudios de Jürgen Habermas (1996) y Maurice Agulhon (2009), entre otros. Para la ciudad de Córdoba contamos con el estudio de Pablo Vagliente (2010), quien identifica, entre 1850 y 1930, la creación de más de mil asociaciones de distinta fisonomía, duración y tamaño; aunque en conjunto muestran un movimiento creciente y sostenido. Según se desprende de su estudio, entre 1870 y 1920 aproximadamente, las agrupaciones culturales emergieron como una novedad, en contraposición con las sociedades y clubes políticos que habían comenzado a formarse desde la época revolucionaria de principios del siglo XIX y que mantenían una presencia casi constante, aunque con grandes altibajos. Fortalecido el movimiento asociativo en general desde 1852, las décadas de 1870 y 1880 verían el auge de las sociedades culturales, desenvuelto, no obstante, en relación conflictiva con la política. En el giro de siglo es notable la transformación desde un marcado "universalismo", que intentaba abrazar "todas las cosas del espíritu" -bellas artes y letras, ciencias, literatura, historia, etc.-, hacia una relativa especialización en la primera década del siglo $\mathrm{XX}$, paralela a la 
emergencia de modalidades de reunión más informales y laxas. Por su parte, las asociaciones recreativas se mantuvieron relativamente constantes en el período y tendrían su belle époque en los años veinte.

No contamos con antecedentes específicos respecto del Club Social; su antigüedad, su actual existencia, su desperdigada presencia en las más diversas fuentes y la cantidad de asociados que reunió -donde podrían verse, por ejemplo, trayectorias de ascenso social inmigrante y déclassement criollo, tramas de relaciones comerciales, alianzas políticas y redes familiares, entre otros aspectos- permitirían entrecruzar investigaciones sobre sociedad, política y economía. Por su parte, el Ateneo de Córdoba ha sido objeto de investigaciones que pusieron de relieve algunas de sus peculiaridades; entre ellas su cercanía con la Universidad, su composición heterogénea dentro de la elite letrada, sus tensiones internas y su perfil universalista (López, 2009).

Por último, con respecto a las fuentes utilizadas, trabajamos con documentos asociativos tales como reglamentos, estatutos y memorias institucionales, todos ellos editados. Lamentablemente, no hemos podido acceder a fuentes inéditas como actas de reuniones o asambleas societarias, ni a otra documentación "interna" de las asociaciones consideradas: en el Ateneo porque no se han conservado y en el Club por no poder acceder a su archivo. ${ }^{1}$ Complementamos nuestro trabajo con otras series documentales, como prensa diaria y revistas.

\section{Club Social: recreación "culta y honesta"}

El Club Social fue fundado el 23 de abril de 1871 -contemporáneamente a la llegada del ferrocarril a la ciudad y a la realización de la primera Exposición Nacionalcon los objetivos explícitos de "cultivar los vínculos de amistad entre los habitantes de la ciudad; fomentar el espíritu de asociación y proporcionar a las personas que lo componen entretenimientos cultos y honestos" (Reglamento, 1876, p. 3). Su creación participaba de la extendida noción epocal de sociabilidad, que era entendida como un rasgo a ser cultivado entre ciudadanos civilizados y "decentes". En tal sentido, el Club fue la primera de varias asociaciones sociales y recreativas locales, como el Jockey Club (fundado en 1885) y el Crisol Club (en 1914), que multiplicaron en el tiempo los ámbitos recreativos de las elites. Asimismo, era similar a otros clubes fundados en distintas ciudades, como los porteños Club del Progreso creado en 1852 y el Jockey Club en 1882 (Losada, 2008) o, unos años más adelante, la rosarina Asociación Cultural El Círculo creada en 1919 (Fernández, 2010). Sin embargo, esta última tiene una marca de clase media-profesional más fuerte, mientras que los primeros reunían a la elite en un entorno orientado a la recreación, el encuentro amable, el estrechamiento de vínculos intraelite y la distinción respecto del resto de la sociedad.

Al momento de su creación, el Club era en Córdoba un "sitio de encuentro para las redes familiares de la notabilidad" (Vagliente, 2010, p. 206). Si bien no se establecían

\footnotetext{
${ }^{1}$ Pese a los reiterados esfuerzos, no logré acceder al archivo institucional del Club Social. Su sede actual conserva un empleado que atiende el teléfono y custodia la puerta que nunca franqueó ante mis consultas. Según sus palabras, dichas por la estrecha rendija que abría, la actividad actual se reduce a que "algunos socios van a media mañana a tomar un café y leer el diario".
} 
requisitos explícitos de ingreso, todo aspirante debía ser presentado por un miembro del Club y aceptado por la asamblea general en votación secreta, y debía abonar una inscripción única de $\$ 25$ y una cuota mensual de $\$ 3$-montos que resultaban elevados para el promedio- (Reglamento, 1876). ${ }^{2}$ Si bien el número de socios fue en aumento desde su fundación, el pago de las mensualidades no siempre se cumplía, y las sucesivas comisiones directivas debían recordarlo regularmente a los socios e implementar medidas para estimularlo.

La ausencia de criterios precisos para el ingreso era ampliamente compensada con la importancia otorgada a la selección de los socios y asistentes, reflejada en las complicadas formas de elaboración de listas de invitados -no socios- a las fiestas del Club que establecía su reglamento. Aunque no se explicitaba, resultaba claro que quienes podían asociarse eran los hombres solteros o casados "cabezas de familia", en cuyo caso sus esposas y familiares eran automáticamente considerados "invitados". Entre otros puntos, era atribución exclusiva del directorio invitar a los "padres de familia" que no fuesen socios y, lo más interesante, elaborar la lista de las familias que eran invitadas a los bailes y recepciones del Club cuyos "representantes" o cabezas de familia no fueran socios. ${ }^{3}$ Estos mecanismos compensaban ampliamente la inexistencia de criterios estrictos para el ingreso, amén de la cuota relativamente cara y la necesidad de presentación, ya que señalaban la exclusividad social del Club. Este llegó a tener 464 socios en 1905 (cantidad que representaba el 0,91\% de la población de la ciudad y el $0,14 \%$ de la provincial) que se sentía como "parte integrante de la sociabilidad cordobesa, porque está incrustada, identificada con ella", en palabras de su presidente. ${ }^{4}$

Las principales actividades eran los bailes y celebraciones. Sus fiestas eran descriptas siempre por la prensa como acontecimientos selectos, en los que se daba cita una concurrencia distinguida. En los salones profusamente decorados e iluminados se celebraban las fiestas patrias como el 25 de Mayo y el 9 de Julio, el Carnaval y otros hitos del calendario social, con números musicales a cargo de una orquesta, animada conversación y baile. En la cotidianidad del Club, se conversaba y se jugaban juegos "lícitos y honestos". En su salón de lectura y su café, que se sumaba a la creciente cantidad de establecimientos de este tipo en la ciudad, se leía y se discutía amenamente. En ocasiones especiales, o bien como parte integral del programa de las fiestas patrias, se realizaban exposiciones artísticas -a veces denominadas "bazares"- y

\footnotetext{
${ }^{2}$ Años después la cuota había variado: "La comisión directiva del Club Social ha resuelto mantener hasta el 20 de mayo próximo la actual cuota de ingreso, que es de 15 pesos, desde esa fecha en adelante la cuota se elevará a 25 pesos. Esta resolución ha sido adoptada para facilitar el ingreso al club de muchos jóvenes que así desean hacerlo". Los Principios, 25 de abril de 1897. Archivo del Arzobispado de Córdoba, Argentina.

${ }^{3}$ En su Reglamento de 1878, ligeramente diferente al de 1876, se establecía: "Todo socio tiene entrada libre y sin necesidad de invitación especial a los bailes, conciertos y otras fiestas"; "Los socios tienen derecho a presentar a las reuniones del Club a sus Sres. Padres, hermanas y señoritas solteras que habiten bajo un mismo techo"; "Todo socio tiene derecho a presentar al Club a señores o familias transeúntes [de paso por la ciudad]. La presentación se hará por escrito al presidente, quien podrá admitirla..."; eran atribuciones del Directorio "Invitar a los bailes del Club a los padres de familia que no sean socios" y "Reunirse con el objeto de hacer la lista de invitación para las familias cuyo representante no sea miembro de este Club, no pudiendo en ningún caso delegar este deber en otra comisión especial ni tampoco convidar a otras familias que las designadas en la lista referida" (Reglamento, 1878).

${ }^{4}$ Memoria del Club Social (2 de julio de 1905). Los Principios.
} 
conferencias literarias. Las primeras exhibían diversos tipos de objetos -no solo dibujos y cuadros sino también trabajos de costura, bordado, pintura de platos, entre otros-, y casi siempre eran organizadas por sociedades benéficas. En ambos casos, se trataba de eventos aislados, a menudo planificados por otra asociación o bien formaban parte de aquellos programas que también incluían concierto, banquete y baile. Esto constituye una diferencia relevante respecto de las actividades específicas del Ateneo como veremos, ya que en él las exposiciones iban acompañadas de concursos con jurados compuestos por pintores reconocidos, premios y gran participación de una incipiente crítica del arte. Asimismo, las conferencias del Ateneo intentaban alcanzar cierta regularidad y se proponían como tribunas abiertas a diversas cuestiones científicas, históricas y culturales, y no solo literarias.

El Club también contaba con una biblioteca, que se habría iniciado con obras donadas por los socios al momento de su ingreso. ${ }^{5}$ En 1881, en la revista E/ Pensamiento publicada por la Sociedad Literaria Deán Funes, se sostenía que esa biblioteca era "pobre, componiéndose en su mayor parte por obras escritas en idiomas extranjeros y con rarísimas excepciones de muy escaso mérito". ${ }^{6}$ Años después, todavía se reseñaban problemas con el catálogo de 1878: había obras perdidas o incompletas y el sistema de préstamos a domicilio era defectuoso (Memoria, 1883). Su salón de lectura, en cambio, estaba bien provisto y recibía numerosos diarios y revistas de Córdoba, Buenos Aires y del extranjero.

En este período el Club tuvo un local céntrico. Inicialmente se trató de una casa en Avenida Gral. Paz N 70 -entre las actuales calles 9 de Julio y Deán Funes-, a la que luego se agregó otra ubicada en 9 de Julio 179-183; ambos locales fueron unidos a través del interior de la manzana. La nombrada institución siempre destinó gran cantidad de espacio a la recreación: contaba con una garçoniere [sic], "una sala agradable con mueblaje apropiado, cuadros y otros adornos, destinándole especialmente para punto de reunión ordinaria del elemento joven"; en ella había una gran mesa de billar y juegos de ajedrez, dominó, chaquette, entre otros. También tenía una toilette para damas y otra para caballeros, un salón de billares profusamente iluminado con mesitas y juegos, una sala de esgrima y otra de baños, un salón de lectura y otro de tertulia. Finalmente, estaba dotado con su propio restaurante y café, que eran atendidos por empleados del Club -y no por damas de sociedades benéficas como ocurría en las actividades públicas del Ateneo-. ${ }^{7}$

Su reglamento no proscribía la discusión política o religiosa, aunque estipulaba que su establecimiento no podría utilizarse para reuniones políticas; sí, en cambio, estaban permitidas las reuniones comerciales. De todos modos, es claro que las cuestiones políticas lograban permear todas las asociaciones, incluso las recreativas. Si bien durante sus primeros diez años, el Club no parece haber estado identificado con

\footnotetext{
${ }^{5}$ En el Reglamento de 1876 no se menciona una biblioteca, pero en el de 1878 se establece que cada socio al ingresar debe donar una obra a la biblioteca y que es atribución del directorio designar un socio como bibliotecario (Arts. $4^{\circ}, 14^{\circ}$ y $29^{\circ}$ ).

${ }^{6}$ El Pensamiento, 11 de septiembre de 1881. Biblioteca Nacional, Buenos Aires, Argentina.

7 Los Principios, 13 de julio de 1900, 28 de diciembre de 1904, 2 de julio de 1905. Aunque excede nuestro período de estudio, mencionamos que según Vagliente (2010) a fines de la década del veinte el Club Social remodeló una vez más y por completo sus instalaciones, y las puso al nivel de los mejores clubes porteños.
} 
ninguna facción política, un joven y ascendente Miguel Juárez Celman, por ejemplo, integró en 1871 -junto con otros doctores de distintas adscripciones políticas- la primera comisión directiva, a la que presidiría en $1876 .{ }^{8}$ Como han señalado Leandro Losada (2008) para Buenos Aires y Pablo Vagliente (2010) para Córdoba, la creación de este tipo de clubes se explica por la relativa pacificación de los vínculos civiles, el encauzamiento de la disputa política a través de canales institucionales y la voluntad de civilización de las costumbres. Sin embargo, tras el ascenso del juarismo, la asociación cordobesa se vuelve lugar de reunión de los hombres de la oposición que, en el nuevo contexto político, "se refugian desilusionados en el hogar y sólo se ven en el Club Social que frecuentan porque se sienten cómodos, ya que la mayoría de sus asociados le da ribetes de entidad opositora" (Sánchez, 1968, p. 212). Por entonces, "el roquijuarismo no tenía entrada en el Club Social" (Díaz de Molina, 1972, p. 496). ${ }^{9}$

A principios del siglo XX, especialmente desde la sanción de la Ley Sáenz Peña en 1912, la institución se mantuvo vinculada, aunque de manera informal, con los sectores conservadores, que por entonces eran mayoría en el Club (Giannone, 2015), y que a partir de ese momento se nuclearon en el Partido Demócrata de Córdoba. Sin embargo, convivían con socios radicales y los eventuales conflictos entre orientaciones políticas diferentes -al momento de la renovación de la comisión directiva, por ejemplo, o al de decidir un homenaje- no llegaban a lesionar la unidad de la asociación. La perdurable vida del Club, al menos en la etapa que se analiza, señala su capacidad de trascender las tensiones políticas, alojar las diversas fracciones de las elites y dar respuesta a su sentida necesidad de contar con un espacio de reunión y sociabilidad que, se entiende, ofrecía más que mera recreación.

\section{Ateneo de Córdoba: alta cultura y sociabilidad intelectual}

El Ateneo de Córdoba se fundó el 19 de agosto de 1894, a partir de una iniciativa letrada orientada a crear una asociación intelectual puramente organizada en torno de una "alta cultura". Esta sirvió como paraguas de las diferencias políticas e ideológicas de sus socios, cuatro años después de la crisis que había acabado con la experiencia juarista (1890) y ocasionó un profundo cimbronazo político y cultural en la ciudad. La etapa juarista comenzaba a ser juzgada, desde esa nueva perspectiva, como un periodo de "euforia materialista", una época intensa signada por el liberalismo y el "progreso"; la nueva etapa se concebía, en relación con dicho proceso, como una grave "reacción" espiritual y moral.

\footnotetext{
${ }^{8}$ La primera comisión directiva del Club estuvo compuesta por ocho miembros, siete de los cuales eran doctores de distintas adscripciones políticas (Díaz de Molina, 1972, p. 496).

${ }^{9}$ Con juarismo nos referimos a los gobiernos provincial y nacional ligados a Miguel Juárez Celman, su hermano Marcos Juárez y a hombres ligados al Partido Nacional Autonomista, exponentes de un momento de gran protagonismo político de Córdoba a nivel nacional. Miguel fue gobernador de la provincia en el lapso $1880-1883$ y presidente de la nación entre 1886 y 1890 . Su hermano Marcos fue gobernador entre 1889 y 1890.
} 
La iniciativa provino de un grupo de profesores universitarios de Derecho que se reunieron con la idea de crear un "Centro de Ciencias Sociales". ${ }^{10}$ Sin embargo, la asociación que finalmente se constituyó tuvo objetivos mucho más amplios. Su estatuto establecía que los fines eran "el Cultivo de las Ciencias, las Bellas Letras y las Bellas Artes", y para ello se realizaban una diversidad de actividades. Las primeras y más regulares fueron las conferencias dictadas por socios o por invitados sobre variados temas. Se brindaron veinticuatro entre 1894 y 1898; se trataba de eventos muy concurridos y que solían incluir una parte musical, aunque en esencia se concebían como una "forma de propaganda y comunicación de ideas; el medio genuino de los Ateneos de todas partes y el más apropiado para la discusión y el cambio de ellas" (Ateneo, 1896). Estos actos, centrales en la vida de la asociación, eran abiertos y de entrada gratuita. Si bien alcanzaron una envidiable regularidad, no fueron las conferencias las actividades más celebradas del Ateneo sino las tres exposiciones y concursos pictóricos que realizó en 1896, 1897 y 1899.

En estas exposiciones se expresó una novedad radical dentro del espectro de consumos culturales disponibles para la elite urbana, al proponer un espacio consagrado a la exhibición y especialmente a la competencia artística, al mismo tiempo que daban cuenta de un estado de situación de las artes plásticas en la ciudad. ${ }^{11}$ En ellas concursaban únicamente aficionados -en su gran mayoría mujeres jóvenes de ese sector social- e integraba el jurado un grupo de artistas reconocidos que, además de exponer en la "sección de artistas", se ocupaban de todo lo referido a bases, reglamentos y premiaciones. Las aperturas y clausuras con entrega de premios eran grandes eventos que convocaban una nutrida asistencia. El año de la primera exposición, el Ateneo realizó además una velada literaria en homenaje al poeta nicaragüense Rubén Darío, quien estaba de paso por la ciudad. Varios miembros de la entidad participaron también de la Comisión promotora del monumento a Dalmacio Vélez Sarsfield -jurista cordobés redactor del primer Código Civil del país-, inaugurado en 1897 con grandes celebraciones públicas y privadas.

Así, los primeros años de vida de esta asociación -desde su creación hasta 1902- fueron de una intensa actividad, siempre reflejada por la prensa diaria que, invariablemente, apoyaba sus iniciativas culturales, aun las fallidas -como la realización de una serie de concursos literarios análogos a los pictóricos o la publicación de una revista-. En esa época también obtuvo una subvención del Estado provincial y se utilizó para acondicionar un local propio, luego de haber funcionado en otros espacios. El Ateneo tenía, como casi todas las asociaciones del período, una sala de lectura con diarios y revistas, pero a diferencia del Club Social, no contaba con café o restaurante en sus instalaciones. Estaba suscripto a los diarios La Patria, La Nación y Los Principios, a la revista La Biblioteca y entre las publicaciones extranjeras recibía la Revue des Revues, la Revue Scientifique y La España Moderna.

\footnotetext{
10 Para una detallada exposición de la creación del Ateneo, ver el primer capítulo de la tesis de María Victoria López (2009).

${ }^{11}$ El antecedente más cercano era la Exposición Nacional de 1871, que entre otras cuestiones había incluido una importante sección de bellas artes y en la que habían participado 11 artistas cordobeses; sobre esa Exposición, ver Malosetti Costa (1999); Nusenovich (2015). Para las exposiciones del Ateneo, consultar López (2009).
} 
Si bien la entidad fue fundada por un grupo reducido de universitarios especialmente vinculados al Derecho, entre sus miembros también contaba con ingenieros, médicos y muy pronto incorporó a artistas -músicos, pintores y "hombres de letras"-, sacerdotes y funcionarios, con lo cual se diversificó el perfil de sus socios. En contraste con el Club Social, sus estatutos establecían precisos criterios de ingreso: en primer lugar eran socios activos del Ateneo los catedráticos de la Universidad y del Seminario Conciliar -institución dependiente del Arzobispado de Córdoba donde se formaban los sacerdotes-; en segunda instancia podían adquirir ese carácter las personas nombradas por la Junta Directiva según sus méritos intelectuales o artísticos; por último se encontraban los aspirantes que, tras presentar un trabajo escrito ante la Junta, podían llegar a ser admitidos luego de la evaluación. La inclusión del Seminario es indicio de una voluntad conciliadora, dado que pocos años antes, en 1881, un conflicto sobre las prerrogativas estatales y eclesiásticas para designar a sus profesores había desembocado en la ruptura definitiva del vínculo entre la Universidad y el Seminario, que hasta entonces había sido relativamente estrecho. Más allá de la presencia de los sacerdotes en la asociación, los criterios de ingreso delimitaban claramente el perfil universitario y letrado, a la vez que abrían la posibilidad de la incorporación de quienes demostrasen sus capacidades o fuesen elegidos por la Junta, independientemente de la posesión de título o cargo docente universitario. A diferencia del Club Social, el Ateneo establecía requisitos explícitos de índole cultural, no bastaba la simple pertenencia estamental para formar parte de la institución.

La cercanía con la Universidad fue uno de sus rasgos centrales, del que derivaba ese perfil intelectual preciso y su voluntad de abarcar todo tipo de manifestación cultural; esta característica constituyó uno de sus aspectos diferenciales en el universo de asociaciones culturales contemporáneas. El Ateneo porteño, por caso, creado en 1892, se orientó rápidamente a la defensa "gremial" de los escritores y los artistas, aunque la extracción social fuera similar a la del Ateneo cordobés (Bibbó, 2014). Las asociaciones culturales bahienses que estudió Agesta (2015), si bien comparten algunos rasgos -el predominio de valores culturales sobre los económicos, el establecimiento de mecanismos específicos de inclusión y exclusión por la vía de las credenciales exigidas y una concepción de la cultura ligada a las bellas artes y la cultura letrada-, presentan diferencias relevantes en relación con el Ateneo. Las sociedades bahienses se orientaron a la creación y consolidación de capitales sociales que legitimaran la inclusión de nuevos sectores sociales profesionales en la elite local, de origen reciente y ligada a la creación misma de la ciudad en 1828. En cambio, en Córdoba, ciudad de antigua fundación (1573) y con una elite colonial establecida, la creación del Ateneo fue obra de los doctores de la Universidad, en su mayoría abogados. Los requisitos de ingreso, insistimos, provenían de esta institución de estudio o eran evaluados según sus criterios, lo mismo que las actividades que se realizaban. Por ello, puede considerarse como expresión del proceso de emergencia de un grupo específicamente cultural-intelectual que se desprende del seno de las elites que hemos caracterizado como "totales".

La Asociación Bernardino Rivadavia, creada en Bahía Blanca en 1882, representó un "ideal reformista" interesado por la educación de los sectores populares -para lo cual creó una biblioteca pública- y por la "modernización de las costumbres" de la sociedad bahiense (Agesta, 2015, p. 4); ambos elementos estuvieron ausentes en el 
Ateneo. La posterior Asociación Cultural Bahía Blanca, fundada en 1919 por comerciantes, profesionales de clase media -en especial, abogados y contadores- y músicos amateurs, promovía conciertos, conferencias y actividades artísticas; ofrecía así "réditos simbólicos y sociales que provenían de su perfil más restringido" (Agesta, 2015, p. 10), aunque en comparación con el Ateneo la cantidad de socios era elevadísima respecto de la población de Bahía Blanca.

Al mismo tiempo, aquella relación del Ateneo de Córdoba con la Universidad no era lineal, pues si bien las marcas de afinidad con la lógica universitaria no eran escasas, la asociación reclamaba su total independencia tanto de ella como de los poderes políticos. ${ }^{12}$ Era una "asociación libre" que aspiraba a ser, en el pensamiento de uno de sus presidentes, refugio y baluarte de la cultura por fuera de toda iniciativa oficial (Ateneo, 1896).

A pesar de establecer esos estrictos criterios de ingreso, la asociación buscaba visibilidad y presencia en la opinión pública. Todas sus actividades eran abiertas al público -no se exigía invitación excepto en pocos casos- y la prensa reseñaba generalmente una gran concurrencia, al menos hasta 1900-1902. En especial, su biblioteca y salón de lectura parecen haber convocado a un público más amplio que el estrictamente universitario. Según una estadística del funcionamiento diario de la biblioteca en el primer semestre de 1899, en ese lapso concurrieron 1981 lectores, de los cuales casi la mitad eran estudiantes, seguidos por empleados, comerciantes y profesores, en ese orden. Abogados e ingenieros figuran últimos en la lista, en tanto que los médicos estuvieron ausentes como categoría particular. ${ }^{13}$ Estos datos sugieren un público ampliado a estudiantes y empleados; la biblioteca del Ateneo aparece, pues, como el más abierto de sus ámbitos: un espacio de sociabilidad intelectual y no meramente de estudio o consulta profesional. En este sentido, se puede ver que lo más leído en ella eran los diarios -un $65,9 \%$ de los lectores según la estadística mencionada-, seguidos por las revistas, lo que da indicios del ambiente que reinaba en la biblioteca: una lectura rápida, diversa y distendida, matizada por la conversación y el debate en torno a lo cotidiano.

Un funcionamiento distinto ofrece en la misma época la biblioteca de la Universidad, que concentraba la lectura "seria" y estudiosa. En el segundo semestre de 1899 tuvo 2629 lectores, un 78\% de los cuales leyó libros -de jurisprudencia, historia, ciencias, etc.- y un $22 \%$ diarios y revistas; un $82 \%$ de ellos eran estudiantes y el $18 \%$ restante se distribuía entre empleados, ingenieros, agrimensores, abogados, médicos, sacerdotes, comerciantes, educadores, periodistas y químicos, en orden decreciente. Esos resultados daban según los autores de la estadística una "somera idea de la cultura general, teniendo en cuenta que los intelectuales leen y estudian en sus

\footnotetext{
12 El rector era presidente honorario de la asociación, todos los catedráticos (titulares y suplentes) eran miembros de pleno derecho, la organización de sus secciones replicaba las facultades existentes en ese momento, inicialmente funcionó en sedes universitarias hasta obtener su propio local, entre otros aspectos (López, 2009).

13 Según esa estadística eran 1471 estudiantes, 251 empleados, 94 comerciantes, 86 profesores, 48 telegrafistas, 15 abogados y 14 ingenieros. Los Principios, 14 de julio de 1899.
} 
bibliotecas particulares y que algunos asistentes tienen también la sala de lectura del Ateneo y las de los numerosos clubs y sociedades de recreo existentes en Córdoba". ${ }^{14}$

Las distintas sedes del Ateneo reflejaban sus múltiples relaciones. Comenzó a funcionar en el Salón de Grados de la Universidad como otras sociedades culturales anteriores, luego el Club Social le prestó tres de sus salones por dos años y declinó la oferta de alquiler de la asociación, hasta que en 1896 obtuvo su propio local en Avenida Gral. Paz N 75, a metros del Club. Llegó a tener 133 miembros y reunió a un heterogéneo conjunto de la elite letrada masculina: allí convivían diferentes posiciones políticas -juaristas, roquistas y radicales-, ideológicas -laicistas y clericales- y estéticas -entusiastas y detractores del modernismo literario-, así como diferentes edades y nacionalidades. Esa convivencia no estuvo exenta de conflictos, alguno de los cuales generó intempestivas renuncias, pero ninguno fue lo suficientemente fuerte como para provocar el fin de la asociación. En el Ateneo se expresaba la capacidad -o la voluntadde reunir a diferentes individuos bajo la apelación a una "alta cultura", universitaria y universalista, que servía para borrar las diferencias que los dividían en otros planos.

No obstante, hacia 1902, la asociación comenzó a decaer. Las exposiciones continuaron realizándose regularmente en su local, pero ahora bajo la organización de la Academia Provincial de Bellas Artes, que surgió en 1896 tras la primera exposición del Ateneo y como oficialización, por parte del gobierno provincial, de la academia particular de Emilio Caraffa creada el año anterior, ya sin ninguna participación de la asociación. Los intentos de reflotar la sociedad en 1901, con la incorporación del emergente Centro de Ingenieros como sección del Ateneo y un fallido proyecto de publicación de una revista, configuraron fracasos que dejaron paso a una silenciosa desaparición, hasta la disolución formal en 1913. Una hipótesis sobre el fin del Ateneo apunta a la multiplicación de competidores más especializados, algunos incluso nacidos de la propia asociación como la mencionada Academia Provincial de Pintura; dos sociedades profesionales amparadas en sus inicios por el Ateneo -el mencionado Centro de Ingenieros y el Círculo de la Prensa creado en 1897- y otras asociaciones más específicas. Tampoco fueron ajenos a su declive los constantes problemas económicos, que incluían una abultada deuda (López, 2009).

\section{Dos asociaciones entre el mundo social y el mundo cultural de las elites}

Decíamos al inicio que entre la pura sociabilidad de la elite y el cultivo de una alta cultura existían zonas de superposición parcial y de exclusión, que contribuían a la delimitación de una fracción cultural de las elites. Un análisis del corpus societario de las asociaciones examinadas, así como un contrapunto entre los criterios de ingreso, objetivos, actividades y autorrepresentaciones, pueden iluminar la cuestión. En primer lugar, la consideración de las listas de socios de estas y otras sociedades muestra la extensión de la plurimembresía entre las elites del giro de siglo y grafica la circulación de un conjunto discreto de personas por ellas: son varios los individuos que pertenecieron a tres, cuatro y hasta cinco instituciones simultáneamente. ${ }^{15}$ Esas

\footnotetext{
${ }^{14}$ Los Principios, 24 de marzo de 1900. Cursiva en el original.

${ }^{15}$ Para un análisis detallado y que comprende más asociaciones, ver López (2019).
} 
pertenencias simultáneas ilustran las diversas facetas de la sociabilidad pública de la elite: por ejemplo, estudiantes de Derecho y miembros de sociedades literarias pertenecían también al Club Social, y alternaban así las áridas discusiones jurídicas con bailes y conciertos. Para ellos, pertenecer al club era quizás un asunto casi familiar, un lugar donde se debían cumplir compromisos de esa índole -posiblemente para estrechar lazos amicales o entablar alianzas con cónyuges apropiados-, mientras que integrar sociedades culturales y literarias podía implicar apuestas culturales, ideológicas y políticas. Del mismo modo, abogados y médicos destacados, con importantes roles en la Universidad, pertenecían tanto al Ateneo como al Club Social.

Un contrapunto entre el Ateneo y el Club Social puede mostrar contactos, superposiciones y exclusiones entre los mundos social y cultural de las elites. En términos de cantidad de asociados y de perdurabilidad, en general las asociaciones recreativas aventajan a las culturales: mientras el Club Social llegó a tener casi 500 socios en 1905 y existe, al menos formalmente, en la actualidad, el Ateneo alcanzó unos 133 miembros en su mejor momento y se extinguió definitivamente en $1913 .{ }^{16}$

Una primera variable a considerar es la existencia de criterios de ingreso: si bien el Club Social no demandaba credenciales específicas y solo establecía al aspirante la necesidad de ser presentado por uno o dos socios de la entidad, las elevadas cuotas de ingreso y mensuales obraban como restricciones prácticas para el acceso. Además, como vimos, se ejercía una estricta vigilancia respecto de las listas de invitados y de visitantes. En cambio, el Ateneo fijaba cuotas accesibles y demandaba explícitamente un determinado perfil societario, aunque establecía diferentes maneras de ingreso profesores universitarios y académicos en primer lugar, seguidos de personas invitadas y por último personas que demostrasen sus capacidades intelectuales mediante la presentación de un trabajo escrito-. El Club Social, como ocurría en general con las sociedades recreativas, incorporaba con relativa facilidad a los inmigrantes que habían logrado integrarse exitosamente en la economía y estaban ya en la vía del ascenso social, mientras que los extranjeros incorporados al Ateneo lo habían sido exclusivamente en función de la posesión de capitales culturales -pintores españoles e italianos, músicos belgas, científicos alemanes-.

Una segunda variable la constituyen los objetivos y las actividades de las asociaciones. El Ateneo se proponía objetivos específicamente ligados al cultivo de la "alta cultura" -ciencia, literatura, "bellas letras" y "bellas artes"-; también a sostener una biblioteca y un salón de lectura provisto de diarios y revistas, y publicar una revista. En términos de acciones, se destacaban las conferencias y especialmente las exposiciones artísticas y las veladas musicales. Ahora bien, tanto el Club Social como otras asociaciones recreativas realizaban el mismo tipo de actividades -conferencias, exposiciones, biblioteca, salón de lectura, bailes de sociedad y celebraciones patrias-. Pero al afinar la mirada se puede reconocer que esas acciones tenían diferente carácter, objetivos y modalidades según se realizaran en una u otra asociación: como decíamos, en el Ateneo las exposiciones eran acompañadas de concursos regidos por pintores

\footnotetext{
${ }^{16}$ Solo hemos detectado quince personas en común entre las listas de socios del Ateneo y el Club Social, muy posiblemente hayan sido más. Es necesario considerar que la reconstrucción de la lista de este último está relativamente incompleta y que esas membresías pueden ser consecutivas o simultáneas, dado que la vida del Social precede y trasciende a la del Ateneo.
} 
reconocidos; en el caso de las conferencias que se realizaban allí eran abiertas al público y buscaban la regularidad, exhibían cierta especificidad temática y exigían pericia a los oradores. Por el contrario, las que se brindaban en el Club Social habitualmente eran parte del programa de una celebración u homenaje que incluía banquete, concierto y baile. Todo lo cual no quita que los oradores y el público asistente fueran, a veces, los mismos -o al menos parcialmente los mismos- en ambas asociaciones.

De igual modo, una comparación de las bibliotecas del Ateneo y el Club Social ilumina las diferentes funciones que estas sociedades otorgaban a esos espacios. Aun con los escasos datos con los que contamos, se perfilan muy diferentes en su composición y uso. La biblioteca y salón de lectura del Ateneo era uno de sus ámbitos más abiertos, recibía diariamente consultas de estudiantes, empleados, comerciantes, profesores y profesionales ajenos a la sociedad. El material más leído en ella eran los diarios y las revistas, eso da la pauta de una lectura distendida y no de un ámbito de estudio; era un espacio abierto y activo que alcanzó a tener 5000 volúmenes, en comparación con lo que parece haber sido una biblioteca apenas activa y compuesta por escasos libros en idiomas extranjeros, que podemos suponer donados al Club debido a su escaso interés. A ello se sumaba un catálogo incompleto y un sistema de préstamos poco aceitado; parecen haber funcionado mejor que la biblioteca el salón de lectura y el bar, provistos de los diarios del día. La lectura del periódico no es una función menor del Club, todo lo contrario: representa la moderna práctica de la lectura diaria realizada fuera del hogar, que con el paso del tiempo se trasladaría a bares y cafés. Por otro lado, la biblioteca universitaria también abrió sus puertas por la noche a partir de 1899 gracias a la iluminación eléctrica, por lo tanto resultaba en esos años un espacio no desdeñable de sociabilidad vinculada a la lectura "seria", con lo cual, entre el Ateneo y la Universidad, se podría haber satisfecho ampliamente esa demanda y dejar para los clubes recreativos, más a la usanza europea, la lectura "liviana".

Por último, es necesario considerar la autorrepresentación de los individuos contemporáneos a esas asociaciones, sus objetivos y actividades: ¿qué encontraban en ellas?, ¿qué imagen de sí mismos cultivaban en cada una? Mientras el Club Social apelaba al fomento de los vínculos de amistad mediante "entretenimientos cultos y honestos", el Ateneo reclamaba un perfil intelectual que rechazaba la frivolidad implícita en ellos; uno de sus presidentes declaraba:

Quien creyera que los Ateneos son asociaciones de hacer fiestas, publicar versos o leer composiciones frívolas y vanas, ve un lado superficial de las cosas y se engaña en el hecho. Si tal fuera no estarían nuestros primeros hombres en sus filas; nuestras ilustradas autoridades no se habrían dignado protegerlas, y la prensa unánime no le habría tributado su caluroso aplauso... está aquí reunida nuestra crema social, los doctores de la casa de Trejo [Universidad Nacional de Córdoba], las autoridades de la Provincia y los dignos representantes de nuestro clero. ${ }^{17}$

La "crema social", los universitarios, el poder político y el religioso, sin embargo, pertenecían tanto a unas como a otras, en tanto miembros de la elite que tienen

\footnotetext{
${ }^{17}$ Discurso del presidente del Ateneo Dr. Moyano Gacitúa (25 de mayo de 1897). Los Principios.
} 
espacios compartidos. Aun cuando tuvieran en común una función de sociabilidad estamental- como fin último, había diferencias entre la espiritualidad que el presidente del Ateneo defendía para su asociación y la "frivolidad" de las fiestas y los versos. Las asociaciones culturales en general hacían gala de trascender las diferencias políticas e ideológicas bajo la invocación de una "alta cultura"; mientras que las asociaciones recreativas se proponían tanto cultivar la amistad y el esparcimiento "decente" intraelite como marcar la distinción de sus miembros respecto del resto de la sociedad, con cuotas caras y mecanismos informales de selección. De esta manera, acompañaban en el plano asociativo la sofisticación de los rituales sociales de la elite.

\section{Conclusiones}

En este trabajo pusimos en consideración dos asociaciones, cada una representativa de modalidades distintas de organización de la sociabilidad asociativa estamental-clasista, para iluminar aspectos desatendidos de la diversificación de las elites en el giro de siglo. Así como este sector se encontraba y compartía en el Club Social -y en tantos otros ámbitos de sociabilidad doméstica y pública-, algunos de sus miembros (no todos) podían además acceder a una "aristocracia del espíritu" fuertemente marcada por la Universidad, pero que sin dudas la trascendía. Las asociaciones consideradas expresan con nitidez un aspecto del proceso de emergencia de la fracción cultural-intelectual de la elite en Córdoba, parcialmente, como consecuencia de una transformación más amplia de las elites totales.

Como muestran las experiencias del Club Social y el Ateneo de Córdoba, con sus singularidades y semejanzas, esta diferenciación interna de las elites se expresó también en sus prácticas de sociabilidad formalizadas en asociaciones. Mientras la pertenencia al estamento -proveniente de la riqueza, el prestigio, el linaje criollo y la titulación universitaria- bastaba para acceder al Club Social, las asociaciones culturales como el Ateneo reclamaban intereses o actitudes tendencialmente culturalintelectuales y ofrecían reconocimientos de ese mismo tipo. Por otro lado, nada de ello impedía que los cruces entre ambas fuesen frecuentes y muy marcada la semejanza entre sus actividades.

Las lógicas progresivamente diferenciadas de los mundos social y cultural de las elites emergen de una consideración global de criterios de ingreso, actividades, objetivos y autorrepresentaciones, y nos revelan las complejidades del asociacionismo estamental-clasista mucho más allá de la distinción genérica. La diferenciación de la fracción cultural respecto de las elites totales, que comenzó a esbozarse en los años noventa del siglo XIX, continuó en el siglo XX. Los intereses culturales de las elites, sin embargo, ya no se expresarían en asociaciones universalistas como el Ateneo; por el contrario, dieron lugar a otras más específicas -como el Centro Musical creado en 1909 por músicos y que organizaba conciertos- o de corte profesional -como el Centro de Ingenieros y el Círculo de la Prensa, ambos nacidos a la sombra del Ateneo, o el Círculo de Autores creado en 1914-. O bien, se expresaron por fuera del mundo asociativo formal y dieron vida a grupos informales de artistas, intelectuales y revistas culturales, que se volverían los espacios de sociabilidad cultural-intelectual más activos a medida que avanzaba el siglo, nutridos por esa nueva fracción cultural que desbordaba 
parcialmente a las elites tradicionales. Los procesos de especialización disciplinar y de diferenciación social del giro de siglo sentaron las bases para la expansión de esos mundos culturales en el siglo $\mathrm{XX}, \mathrm{y}$ el movimiento asociativo, así como algunas asociaciones en particular, lo expresaron nítidamente.

\section{Referencias bibliográficas}

1. Agesta, M. N. (2015, 13 de mayo). Modernismo de gente bien. Asociacionismo intelectual y cultura de élite en Bahía Blanca (1882-1930) [ponencia]. V Jornadas Nacionales de Historia Social. La Falda, Argentina.

2. Agüero, A. C. y López, M. V. (2017). De la Sociedad Literaria Deán Funes a la Asociación Córdoba Libre. Dos estaciones del liberalismo y las elites de Córdoba (1878/1919). Boletín del Instituto de Historia Argentina y Americana "Dr. Emilio Ravignani", 47, 137-165.

3. Agulhon, M. (2009). El círculo burgués. La sociabilidad en Francia, 1810-1848. Siglo XXI. (Edición original 1977).

4. Altamirano, C. (2008). Historia de los intelectuales en América Latina, Vol. I. Katz.

5. Ateneo de Córdoba (1896). Memoria presentada a los socios del Ateneo en la asamblea general reunida en el $2^{\circ}$ aniversario de la fundación del mismo. La Moderna. Biblioteca de la Facultad de Filosofía y Humanidades, Universidad Nacional de Córdoba, Córdoba, Argentina

6. Bibbó, F. (2014). El Ateneo (1892-1902). Proyectos, encuentros y polémicas en las encrucijadas de la vida cultural. En P. Bruno (Dir.) Sociabilidades y vida cultural. Buenos Aires, 1860-1930 (pp. 219-250). Universidad Nacional de Quilmes.

7. Bloch, M. (1993). Para una historia comparada de las sociedades europeas. En G. Godoy y E. Hourcade (Eds.) Marc Bloch. Una historia viva. Centro Editor de América Latina.

8. Bruno, P. (2014). Sociabilidades y vida cultural. Buenos Aires, 1860-1930. Universidad Nacional de Quilmes.

9. Díaz de Molina, A. (1972). La oligarquía argentina. Su filiación y su régimen (1840-1898). Ediciones Pannedille.

10. Fernández, S. (2010). La Revista El Círculo o el arte de papel. Una experiencia editorial en la Argentina del Centenario. Ediciones de la Universidad de Murcia.

11. Giannone, L. (2015, 13 de mayo). Las estrategias de construcción y conservación 
del poder de la elite conservadora en el interior del Partido Demócrata de la provincia de Córdoba (1912-1916) [ponencia]. V Jornadas Nacionales de Historia Social. La Falda, Argentina.

12. González Bernardo de Quirós, P. (2001). Civilidad y política en los orígenes de la Nación Argentina. Las sociabilidades en Buenos Aires, 1829-1862. Fondo de Cultura Económica.

13. Habermas, J. (1996). Historia y crítica de la opinión pública. Gustavo Gilli.

14. Hora, R. (2014). Historia del turf argentino. Siglo XXI.

15. López, M. V. (2009). Elite letrada y alta cultura en el fin de siglo. El Ateneo de Córdoba, 1894-1913 [tesis de licenciatura, Universidad Nacional de Córdoba, tesis no publicada].

16. López, M. V. (2019). Elites, sociabilidad y "alta cultura" en Córdoba, 1870-1918 [tesis de doctorado, Universidad Nacional de Córdoba, tesis no publicada].

17. Losada, L. (2008). La alta sociedad en la Buenos Aires de la Belle Epoque. Sociabilidad, estilo de vida e identidades. Siglo XXI.

18. Losada, L. (2009). Historia de las elites en la Argentina. Desde la conquista hasta el surgimiento del peronismo. Sudamericana.

19. Malosetti Costa, L. (1999). Las artes plásticas entre el ochenta y el Centenario. En J. E. Burucúa (Dir.) Nueva Historia Argentina. Arte, sociedad y política. Sudamericana.

20. Martínez, A. T. (2006). Entre el notable y el intelectual. Las virtualidades del modelo de campo para analizar una sociedad en transformación (Santiago del Estero 1920-1930). Cuadernos de la Facultad de Humanidades y Ciencias Sociales, 37, 95-113.

21. Memoria de la administración del "Club Social" de Córdoba (1883). Presentada a la sociedad por el Directorio elegido el $1^{\circ}$ de julio de 1882. Imprenta del Eco de Córdoba. Biblioteca Nacional, Buenos Aires, Argentina.

22. Nusenovich, M. (2015). Arte y experiencia en Córdoba en la segunda mitad del $X I X$. Editorial de la Universidad Nacional de Córdoba.

23. Reglamento del Club Social (1876). Establecimiento Tipográfico Rivas de Córdoba. Biblioteca Nacional, Buenos Aires, Argentina. 
24. Reglamento del Club Social (1878). Establecimiento Tipográfico Rivas de Córdoba. Biblioteca Nacional, Buenos Aires, Argentina.

25. Sánchez, E. (1968). Del pasado cordobés en la vida argentina. Biffignandi.

26. Vagliente, P. (2010). Sociedad civil, cultura política y debilidad democrática. Córdoba, 1852-1930 [tesis de doctorado, Universidad Nacional de Córdoba, tesis no publicada].

27. Vignoli, M. (2015). Sociabilidad y cultura política. La Sociedad Sarmiento de Tucumán, 1880-1914. Prohistoria.

28. Zimmermann, E. A. (2000). La sociedad entre 1870 y 1914. En Nueva Historia de la Nación Argentina, Tomo IV. La configuración de la República independiente (1810-c.1914). Academia Nacional de la Historia/Planeta. 